\title{
A peculiar chimera
}

\author{
Health Care Federalism in Canada: Critical \\ Junctures and Critical Perspectives \\ Katherine Fierlbeck, William Lahey, editors \\ McGill-Queen's University Press; 2013.
}

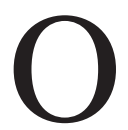
ne chapter into Health Care Federalism in Canada: Critical Junctures and Critical Perspectives, I was distracted from my intended mission: to consider this book on the merits of its writing and the coherence of its arguments. Instead, I began to wonder about the timing of this collection of essays.

In 2011, the federal government decreed that in 2015 federal transfers to the provinces for health care would be disbursed on a growth-indexed, per-capita basis without any attached conditions. With this tsunami on the horizon, it would seem timely to examine the seaworthiness of Canadian health care as a subsystem of our federal state.

Editor Katherine Fierlbeck, a professor of political science at Dalhousie University in Halifax, begins by examining the extensive history of the issue: the Hospital Insurance and Diagnostic Services Act of 1957, the Medical Care Act of 1966 and the Canada Health Act of 1984, federal and provincial health care agreements struck in 2001 and 2003, and in 2004 the creation of $A$ 10-year Plan to Strengthen Health Care. How have we neglected to consider all of this in the context of Canadian federalism before now, and is there still time to prepare?

Canadian federalism is a peculiar chimera - 13 unruly heads on a single lumbering body - that is among the most decentralized such arrangements in the world. How do we subdue this beast? Health Care Federalism offers opinions from across the spectra of economic and political thought; there is something to applaud and something to

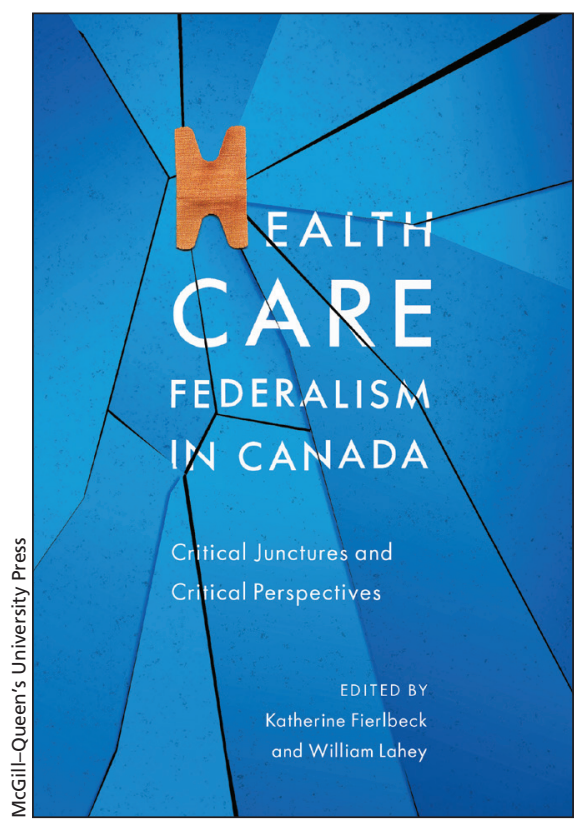

deplore for all but the most libertarian of readers. Some opinions are delivered in academic bafflegab, others in ideological jargon, but some come in packaging both readable and sensible, most notably David Haardt's chapter, "Economic Trends and Challenges."

Haardt, a professor at the School of Health Administration at Dalhousie, gets nearer than any of Health Care Federalism's other authors to a practical consideration of the matter by asking simple questions: Should health care be considered a consumer good or a necessary service? Is strict per-capita allocation of transfers fair to provinces that have higher proportions of medically expensive senior residents? If the Canadian constitution never mentions "health" and its blueprint for federal and provincial relations comes from a time when health care had none of its current complexity, is the current arrangement still relevant? Might the important dividing line in health care be one drawn, not between provinces, but between urban and rural populations? I finished Haardt's essay with more questions than answers, but with the conviction that a sensible question is worth many "answers" that are based in scholarly or partisan ideology.

The discussion is occurring in academia and politics, not on the front lines. Given the breadth of opinions represented here, it's surprising that there is none from anyone who actually works in health care. (Dalhousie nursing professor Gail Tomblin Murphy is the only author who has trained or worked as a clinician, but she writes here as an expert on human resources planning.) I don't know if any of the authors has ever been a patient; I can say with certainty that they all will be eventually. Patient perspectives, however, get little mention. Insomuch as Health Care Federalism is a roundtable discussion, many stakeholders are voiceless by virtue of absence. (Maybe this is unfair, because taxpayers are considered extensively, cast either as agents or as victims.)

Is this book just in time to ignite a much-needed larger conversation or is it a tome too late? Stephen Lewis observes that there is a "Hobbesian bargain in federalism: the provinces agree to let Ottawa impose conditions in some areas to save themselves from each other. But first they need to think that they need saving, and second that Ottawa is a reliable lifeboat." But this metaphor, and my own - the chimera - are incomplete. Federalism is not simply about the federal and provincial governments, and health care especially is not limited to that dyad. We must include the wretched parasites who live on the beast, who get sick and who give care. Have we the time to consider these minute souls?

Paul Moorehead MD

Janeway Children's Health and

Rehabilitation Centre, St. John's, NL 